\title{
Family history and risk of breast cancer
}

\author{
R S Houlston, E McCarter, S Parbhoo, J H Scurr, J Slack
}

\begin{abstract}
The risk of breast cancer in first degree relatives of patients with breast cancer can be derived from family history and is dependent upon the age at diagnosis in the index patient. For the relatives of index patients older than 55 , the relative risk is 1.57 , if less than 55 the relative risk is $2 \cdot 29$, and $3 \cdot 85$ if less than 45 (95\% confidence limits 0.83 to $2 \cdot 68,1 \cdot 18$ to $4 \cdot 01$, and 1.67 to 3.85 , respectively). First degree relatives of patients with bilateral breast cancer have a 6.43 -fold increase in risk (95\% confidence limits $1 \cdot 32$ to $18 \cdot 77)$. The genetic contribution to overall lifetime liability to breast cancer in the relatives declines rapidly with increasing age of onset of breast cancer in the index patient from $37 \%$ at 20 years to $8 \%$ by 45 years. This information can be used in clinical practice for counselling and the establishment of screening programmes.
\end{abstract}

Cancer of the breast is a common malignancy in women, and while environmental and reproductive experience plays a significant role in its aetiology, family history has long been recognised as an important risk factor. ${ }^{12}$ Family studies have identified clustering of breast cancer, in association with ovarian cancer, ${ }^{2}$ and colon and other cancers, and some of these pedigrees are compatible with the Lynch type II cancer family syndrome, ${ }^{3}$ which is recognised as having an autosomal dominant mode of inheritance. Epidemiological studies have shown an overall increase in breast cancer in relatives of patients with breast cancer. ${ }^{4-11}$ Furthermore, there is evidence of dominant inheritance of a liability to breast cancer with an estimated gene frequency of $0.3 \%$ and penetrance of $83 \% .^{12}$ It is therefore not surprising that breast cancer is a cause of concern to a large number of women, especially in whom there is a family history of breast and other cancers. ${ }^{13}$

The purpose of this study was to determine the risks of breast and other cancers in first degree relatives of patients with cancers of the breast at different ages, and to identify high risk subjects who may benefit from entering a screening programme based on an estimate of their risk.
Patients and pedigrees

Two hundred and fifty-four consecutive pedigrees were ascertained through women diagnosed with histologically proven breast cancer attending follow up breast clinics at the Royal Free Hospital and University College Hospital. The first 204 were unselected cases but the last 50 were selected for premenopausal onset. No pedigree was selected for family history. Pedigrees were all taken by a single pedigree worker. One pedigree was excluded from analysis because of insufficient information on family members.

Of the 166 deaths in first degree relatives from all types of cancer, $130(78 \%)$ were verified by death certificates or hospital records, and in 26 first degree relatives alive with cancer the diagnosis was verified from hospital records in $14(56 \%)$. Data on living relatives with cancer were only recorded for the purpose of syndrome identification and not for estimation of risks.

Index patients were divided into those who developed breast cancer before 45,50 , and 55 , and those who developed it after 55. Of the 20 patients who developed breast cancer between the ages of 50 and 54, 11 were reported to be premenopausal.

\section{Calculation of risks}

Standard life table methods ${ }^{14}$ were used to estimate the years of risk by decade contributed by female and male first degree relatives of patients diagnosed with breast cancer. Life tables were drawn up separately for mothers, sisters, and daughters. The experience of male first degree relatives was separated as a single group.

Tables from the Office of Population Censuses and Surveys (OPCS) were used to calculate the expected number of deaths among first degree relatives in 10 year age groups from the age of 15 . The relative risk of death from all causes, death from all cancers, and death from breast, ovarian, uterine, lung, colorectal, prostate, and stomach cancers was calculated. The significance of any difference between the observed and expected numbers of deaths was determined using the Poisson statistic ${ }^{15}$ and $95 \%$ confidence limits of relative risks were obtained from the table in Breslow and Day. ${ }^{16}$

The genetic and sporadic components to overall risk for first degree relatives and their relationship to age of onset of breast cancer in 
index patients was determined from an estimate of gene penetrance and frequency in different age groups. ${ }^{12}$ The genetic component to risk is the product of the probability of inheriting the gene and the penetrance of that gene. The sporadic component is derived from the product of the likelihood of not having the gene and the incidence of breast cancer.

\section{Results}

These index patients provided a total of 32085 years at risk in female first degree relatives and 28475 in males.

The observed number of deaths from breast cancer and relative risks are shown in the table. Overall the relative risk of breast cancer in first degree relatives of all index patients is 1.85 but is most marked for those relatives of index patients less than 45 years old. Furthermore, for relatives of patients diagnosed before 55, a $2 \cdot 84$-fold increase in risk is seen before the age of 55. There were no breast cancer deaths in sisters or daughters of patients diagnosed with breast cancer below the age of 55 . It should be noted that the number of years at risk for sisters and daughters of patients diagnosed before 55 is only 5765 and 1070 , respectively, with a correspondingly low expected number of deaths from breast cancer of 1.56 and 0.06 .

Overall an increased risk for sisters was seen, but this was not significant (relative risk $=1.31,95 \%$ confidence limits 0.52 to $2 \cdot 70$ ). Daughters showed a $5 \cdot 88$-fold increase in risk overall, which was statistically significant $(p<0.05,95 \%$ confidence limits 0.71 to 21.22 ), but was dependent on only two observed deaths in daughters under 55 .

Observed numbers of deaths from all causes are not different from the expected for either males or females. The observed numbers of deaths and relative risks for all female and male first degree relatives for all deaths, all cancers, cancers of the ovary, uterus, colorectum, lung, and prostate were investigated.

The pattern of increased risk of breast cancer was reflected in the relative risk for all cancers in women. The relative risk for those relatives of patients diagnosed before 55 was 1.43 ( $p<0.05,95 \%$ confidence limits 0.98 to $2 \cdot 02)$ and $1 \cdot 13(p>0 \cdot 1,95 \%$ confidence limits 0.32 to 1.52 ) if diagnosed with breast cancer at or older than 55 . From the complete pedigree analysis, no other significant increase in any other cancers was seen in female first degree relatives.

Death from breast cancer observed $(O)$ and relative risk $(R R)$ in first degree relatives.

\begin{tabular}{|c|c|c|c|c|c|c|c|c|c|c|}
\hline \multirow{3}{*}{$\begin{array}{l}\text { Age of } \\
\text { first } \\
\text { degree } \\
\text { relative }\end{array}$} & \multicolumn{8}{|c|}{ Age at diagnosis of breast cancer in index patient } & \multirow{2}{*}{\multicolumn{2}{|c|}{$\begin{array}{l}\text { All index } \\
\text { patients }\end{array}$}} \\
\hline & \multicolumn{2}{|c|}{$<45$} & \multicolumn{2}{|c|}{$<50$} & \multicolumn{2}{|c|}{$<55$} & \multicolumn{2}{|c|}{$>55$} & & \\
\hline & $\mathbf{O}$ & $\mathbf{R R}$ & $\mathbf{O}$ & $\mathbf{R R}$ & O & $\mathbf{R} \mathbf{R}$ & $\mathbf{O}$ & $\mathbf{R R}$ & $\mathbf{O}$ & $\mathbf{R R}$ \\
\hline $\begin{array}{l}<55 \\
>55 \\
\text { All }\end{array}$ & $\begin{array}{l}3 \\
5 \dagger \\
6 \dagger\end{array}$ & $\begin{array}{l}3 \cdot 22^{\mathrm{a}} \\
4 \cdot 36^{\mathrm{b}} \\
3 \cdot 85^{\mathrm{c}}\end{array}$ & $\begin{array}{c}5^{*} \\
5 \\
10^{*}\end{array}$ & $\begin{array}{l}2 \cdot 92^{\mathrm{d}} \\
2 \cdot 06^{\mathrm{e}} \\
2 \cdot 42^{\mathrm{f}}\end{array}$ & $\begin{array}{r}6^{*} \\
6^{*} \\
12+\end{array}$ & $\begin{array}{l}2 \cdot 84^{\mathrm{g}} \\
1 \cdot 92^{\mathrm{h}} \\
2 \cdot 29^{\mathrm{i}}\end{array}$ & $\begin{array}{c}3 \\
10^{*} \\
13\end{array}$ & $\begin{array}{l}1.08^{j} \\
1.83^{k} \\
1.57^{1}\end{array}$ & $\begin{array}{c}9 \\
16^{*} \\
25 \dagger\end{array}$ & $\begin{array}{l}1 \cdot 84^{\mathrm{m}} \\
1 \cdot 86^{\mathrm{n}} \\
1 \cdot 85^{\circ}\end{array}$ \\
\hline
\end{tabular}

$95 \%$ confidence limits of RR a (0.66-9.40), b (1.41-10.16), c (1.66-7.58), d (0.95-6.80), e $(0.66-4 \cdot 80)$, f $(1 \cdot 16-4 \cdot 45)$, g $(0 \cdot 77-4 \cdot 60)$, h $(0 \cdot 70-4 \cdot 18)$, i $(1 \cdot 18-4 \cdot 01)$, j $(0 \cdot 22-3 \cdot 15)$, $\mathrm{k}(0 \cdot 87-3 \cdot 37), \mathrm{l}(0.83-2 \cdot 68), \mathrm{m}(0 \cdot 84-3 \cdot 50), \mathrm{n}(1.06-3 \cdot 01), \mathrm{o}(1 \cdot 20-2 \cdot 74)$

Significance of difference from expected ${ }^{*} \mathrm{p}<0.05,+\mathrm{p}<0.01$.
There was an increase in relative risk for male first degree relatives for prostatic cancer with a $2 \cdot 36$-fold increase in risk overall seen ( $\mathrm{p}<0.05,95 \%$ confidence limits $1 \cdot 13$ to $4 \cdot 34$ ). Paradoxically, lung cancer showed a significant reduction in relative risk in men (relative risk $0.48, \mathrm{p}<0.001,95 \%$ confidence limits 0.26 to 0.81$)$. No other significant difference in risk of other cancers was found.

In this study, 15 index patients developed breast cancer bilaterally and three of the patients were from pedigrees showing dominant inheritance. In 10, the first breast cancer had developed premenopausally and five postmenopausally. For first degree female relatives of premenopausal patients, there were 865 years at risk, two deaths from breast cancer, and the relative risk was $7 \cdot 78(\mathrm{p}<0.05,95 \%$ confidence interval 0.94 to 28.08 ). For those first degree relatives of postmenopausal patients, there were 500 years at risk, one breast cancer death, which was not significantly different from expected, and the relative risk was 4.78 (95\% confidence limits 0.12 to 26.62). For all first degree relatives of all 15 patients, the relative risk of breast cancer was $6.43(\mathrm{p}<0.05,95 \%$ confidence limits 1.32 to 18.77).

Two pedigrees were compatible with the dominant inheritance of early onset breast cancer termed site specific breast cancer as described by Lynch and Lynch. ${ }^{2}$ Eleven pedigrees were characterised by the dominant inheritance of a variety of cancers often described as Lynch type II cancer family syndrome. ${ }^{317}$

From the calculation of Iselius et al, ${ }^{12}$ who included this series of pedigrees, the probability of inheriting a single gene with large effect for breast cancer if the index patient is between 20 and 24 is $45 \%$ which, with a penetrance of $83 \%$, gives a lifetime genetic risk of $37 \%$ of developing breast cancer. Fig 1 shows the derived genetic component and total overall lifetime risk of breast cancer for first degree relatives of index patients at varying ages of onset. The genetic risk is greatest for those relatives of patients who develop breast cancer young. For relatives of an index patient diagnosed with breast cancer at 45 , the genetic risk of breast cancer in the first degree relative has dropped from $37 \%$ to $8 \%$. Fig 2 shows the total lifetime probability of developing breast

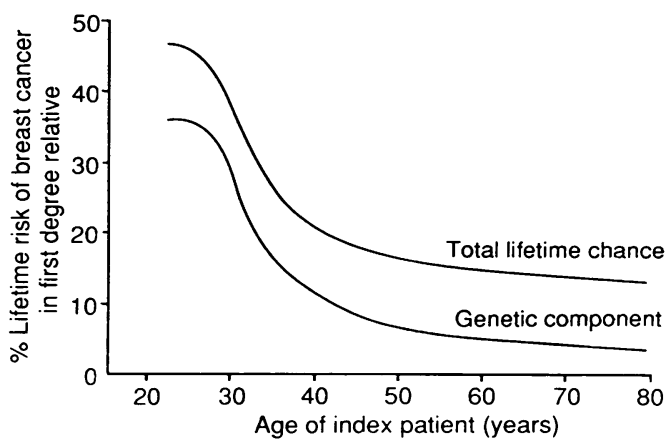

Figure 1 Genetic component and total lifetime risk for breast cancer in first degree relatives in relation to age of diagnosis of breast cancer in index patient. 


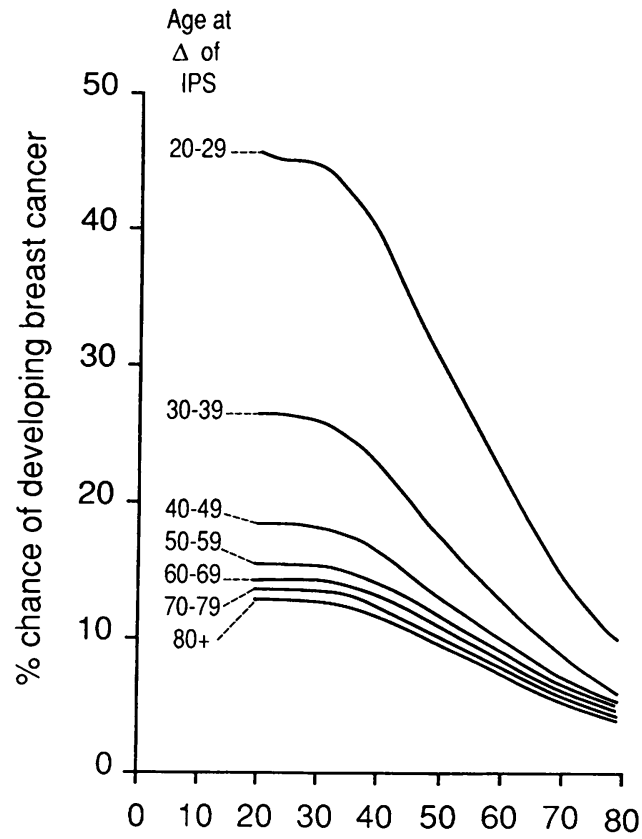

Age of first degree relative (years)

Figure 2 Total lifetime probability of developing breast cancer with increasing age in relation to age of diagnosis $(\triangle)$ in index patients (IPS).

cancer with increasing age in relatives of patients diagnosed at different ages, assuming that the age of onset for those genetically susceptible within families is independent of the age of onset in the phenocopies. Fig 3 shows the actual risk over 10 years of developing breast cancer with increasing age in relation to age of diagnosis in index patients. There are two components to risk. The risk from the genetic component is greatest after

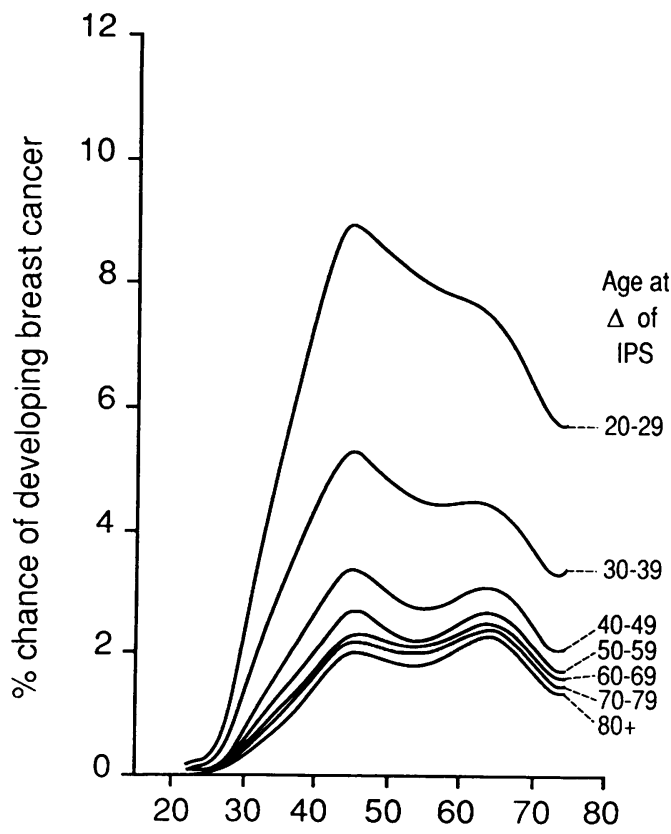

Age of first degree relative (years)

Figure 3 Actual risk over 10 years of developing breast cancer with increasing age in relation to age of diagnosis $(\triangle)$ in index patients (IPS). the age of 30 for those who are relatives of patients diagnosed young. However, later in life, the greater part of the risk is sporadic when the increasing phenocopy rate offsets the decreasing role of genetic susceptibility.

\section{Discussion}

The results from this analysis of pedigrees are in general agreement with a number of previous studies which have shown an increased risk of breast cancer in first degree relatives of patients with breast cancer..$^{6-11}$ Relative risks were dependent upon the age of the index patient being greater for those relatives of index patients less than 45, approximating to premenopausal status. This is in keeping with the original pattern described by Anderson ${ }^{5}$ and confirmed by some ${ }^{8}$ but not other workers. ${ }^{67}$

A small number of pedigrees were compatible with the diagnosis of site specific or hereditary breast cancer in which there was sufficient information from the pedigree to infer that the primary aetiological factor was likely to be a genetic one.

An increased risk to first degree relatives of patients with bilateral breast cancer has been reported, ${ }^{56}$ while other workers have been unable to show this. ${ }^{7}$ Our study supports the view that the presence of bilateral breast cancer indicates a considerable increase in risk to first degree relatives and may suggest a high genetic predisposition.

Previous studies have reported a higher risk for sisters than for mothers of breast cancer patients. ${ }^{6}$ While numbers in our study are small, we found no support for this observation. However, it is likely that any genetic inferences from such empirical data comparing relative risks are inappropriate since relative risks for sisters and daughters are likely to be distorted by the very low expected values.

This same set of pedigrees together with a selected series have been used to derive a possible mode of inheritance of breast cancer and an estimate of gene frequency. ${ }^{12} \mathrm{~A}$ dominant gene is most likely with a frequency of $0.3 \%$ with $83 \%$ penetrance. These results are in keeping with estimates from other studies. ${ }^{1819}$ These data enabled us to calculate the likely genetic and sporadic components of risk at different ages to first degree relatives of patients diagnosed with breast cancer at different ages, and our results are consistent with those recently reported. ${ }^{19} \mathrm{With}$ an early age of onset, the genetic risk to offspring is high, but with increasing age of onset this component of overall risk rapidly diminishes; however, with increasing age of the relative the risk of any inherited liability is reduced. In clinical practice, this information can be used to identify more precisely those family members who are at risk and to estimate the chance that a dominant gene is responsible for any family aggregation of breast cancer.

Lynch et $a l^{3}$ have drawn attention to the increased risk of breast and gynaecological cancers in the cancer family syndrome from studies of a few large kindreds. Other workers 
have shown that this increased risk extends to a large number of families with a lifetime risk of developing breast cancer for first degree relatives of 1 in $3 \cdot 7 .^{17}$

Previous studies reporting a relationship between breast cancer and other cancers are conflicting, but an association between pancreatic, colon, and breast cancer has been shown in some studies, ${ }^{2021}$ which may reflect the contribution of the Lynch type II cancer family syndrome to the development of breast cancer. In this study, $4.3 \%$ of pedigrees were compatible with the Lynch type II cancer family syndrome.

In the absence of any biomarker for either hereditary site specific breast cancer or Lynch II cancer family syndrome, recognition in clinical practice of high risk relatives is at present dependent solely upon taking an adequate family history.

Although at least $8 \%$ of cases of breast cancer may result from an inherited liability, ${ }^{12}$ the majority of breast cancer is sporadic and the population risks are highest overall for those women over the age of 50 . This underlies the availability of breast screening to women through the national screening programme. However, there is an equivalent risk of 1 in 8 of developing breast cancer below the age of 50 for those relatives of patients diagnosed before 45. While the percentage of women developing breast cancer under 45 is small, it is not insignificant. In 1985, 2676 women were diagnosed with breast cancer before the age of 45.22 Since a woman has on average 2.4 close female relatives, there are approximately 6422 women at higher risk in whom around 2055 would be expected to develop breast cancer in their lifetime.

Clearly there is an opportunity to identify women at risk through their family history in whom screening may be of benefit, starting at an earlier age than currently being offered through the national screening programme.

Both R S Houlston and E McCarter were funded by the Imperial Cancer Research
Fund. We would like to thank J Grimsey for help in preparing the manuscript.

1 Larson E. Epidemiological correlates of breast, endometrial and ovarian cancers. Cancer Nursing 1983:295-301.

2 Lynch HT, Lynch JF. Breast cancer genetics. In: Familial cancer. 1st International Research Conference, Basel 1985. Karger: Basel, 1985:20-4.

3 Lynch HT, Laanspa SJ, Boman BM et al. Hereditary nonpolyposis colorectal cancer-Lynch syndromes I and II Gastroenterol Clin North Am 1988;17:679-712.

4 Anderson DE. Some characteristics of familial breast cancer. Cancer 1971;28:1500-4.

5 Anderson DE. Genetic study of breast cancer: identification of a high risk group. Cancer 1973;34:1090-7.

6 Ottman R, Pike MC, King M, Henderson BE. Practical guide for estimating risk for familial breast cancer. Lancet 1983;ii:556-8.

7 Sattin RW, Rubin GL, Webster LA, et al. Family history and risk of breast cancer. $\mathcal{F} A M A 1985 ; 253: 1908-13$.

8 Ottman R, Pike MC, King M, Casagrande JT, Henderson BE. Familial breast cancer in a population-based series. Am $\mathcal{f}$ Epidemiol 1986;123:15-21.

9 Dupont WD, Page DL. Breast cancer risk associated with proliferative disease, age at first birth, and a family history of breast cancer. Am $\mathcal{f}$ Epidemiol 1987;125:769-79.

10 Negri E, LaVecchia C, Bruzzi P, et al. Risk factors for breast cancer: pooled results from three Italian casecontrol studies. Am $\mathcal{f}$ Epidemiol 1988;128:1207-15.

11 Bouchardy C, Le MG, Hill C. Risk factors for breast cancer according to age at diagnosis in a French case-control study. F Clin Epidemiol 1990;43:267-75.

12 Iselius L, Slack J, Littler M, Morton NE. Genetic epidemiology of breast cancer in Britain. Ann Hum Genet 1991; 55:151-9.

13 Fallowfield LJ, Rodway A, Baum M. What are the psychological factors influencing attendance, non-attendance and re-attendance at a breast screening centre? $\mathcal{f} R$ Soc Med 1990;83:547-51.

14 Bradford Hill A. In: Principles of medical statistics. London: The Lancet Ltd, 1961:220-36.

15 Pearson ES, Hartley HO. Biometrika tables for statisticians. Vol 1, 3rd ed. Cambridge: Cambridge University Press, 1966.

16 Breslow NE, Day NE. Statistical methods in cancer research Chapter 2. Lyon: WHO, IARC Publications, 1987.

17 Itoh H, Houlston R, Harocopos C, Slack J. Risk of cancer death in first degree relatives of patients with hereditary non-polyposis cancer syndrome (Lynch type II). A study of 130 individuals in the United Kingdom. Br $\mathcal{F}$ Surg of 130 individual

18 Iselius L, Littler $M$, Morton NE. Transmission of breast cancer - a controversy resolved. Clin Genet (in press).

19 Claus EB, Risch N, Thompson WD. Genetic analysis of breast cancer in the cancer and steroid hormone study. Am ₹ Hum Genet 1991;48:232-42.

20 Schimke N. Dominant inheritance in human cancer. In: Chaganti RSK, German J, eds. Genetics in clinical oncology. Oxford: Oxford University Press, 1985:103-21.

21 Lynch HT, Marcus JM, Watson P, Conway T, Fitzsimmons ML, Lynch JF. Genetic epidemiology of breast cancer. In: Lynch HT, Hirayama T, eds. Genetic epidemiology of cancer. Boca Raton: CRC Press, 1989.

22 Office of Population Censuses and Surveys. Cancer statistics 1985. England and Wales. London: HMSO, 1985. 